dependerá das questões que se deseja colocar à nossa "civilização tecnológica". E como nota Garcia dos Santos nas primeiras frases de seu texto (p.149): "O referencial de boa parte daqueles que esperam da bioética uma resposta às 'questões alarmantes' trazidas pelo progresso da ciência e da tecnologia contemporâneas é o do humanismo moderno. Seria o caso, contudo, de indagar se o avanço da tecnociência já não tornou obsoletos os critérios que balizavam a concepção moderna do homem."

Ecológicas manhãs de sábado - o espetáculo da natureza na televisão brasileira

Thales de Andrade.

São Paulo, Annablume, 2003. 240p.

\section{NATUREZA E ECOLOGIA NA TELEVISÃO BRASILEIRA}

\section{TELMA DOMINGUES DA SILVA *}

Esta obra é uma contribuição, ao mesmo tempo, para a reflexão sobre a mídia, em seu papel e seus efeitos na sociedade contemporânea, e para uma compreensão do meio ambiente como questão política, dada a forma como o autor delimitou seus questionamentos nesse trabalho de pesquisa desenvolvido como tese de doutoramento na área das Ciências Sociais.

* Doutora em Lingüística pelo IEL/UNICAMP e pesquisadora colaboradora do Laboratório de Estudos Urbanos da UNICAMP.
Analisando dois programas de televisão que têm a natureza como tema, Thales de Andrade discute o papel dos meios de comunicação na formulação de problemas e questões ambientais. Interessa ao autor investigar relações entre as transformações na conjuntura econômico-política do país e a imagem da natureza veiculada através da mídia. Amaral Neto, o repórter e Globo Ecologia, ambas produções da Rede Globo de televisão, foram exibidas em momentos históricos diferentes e são exemplares de uma mudança radical que se verifica sobre o sentido da natureza como objeto de reportagem para o público brasileiro.

A seleção desses dois programas foi adequada, justamente com relação à conjuntura econômico-política do país em que eles se produziram.

A exibição de Amaral Neto se deu nas décadas de 1960 e 1970, momento em que o país é direcionado pelo projeto político e econômico desenvolvimentista do governo militar. Amaral Neto teve carreira política como deputado durante essa época. É representante de um pensamento conservador sobre a abordagem das questões ambientais, realizando em seus programas uma determinada apologia das riquezas naturais brasileiras.

O programa Globo Ecologia, por sua vez, será exibido a partir de 1990, isto é, depois de haver uma ruptura em relação ao regime político ditatorial no governo militar, ruptura significada pela Constituição de 1988, que reinstala as eleições e demais direitos democráticos. A introdução na televisão institucionalizada de uma abordagem jornalística a partir do tema ecologia é sintomática, marcando o contexto político 
que se constitui posteriormente à abertura democrática como um "novo tempo".

Assim, o tema ecologia desloca-se de um lugar politicamente marginal de discussão e passa a se constituir em seção jornalística. Estar na televisão, através da Rede Globo, é estar no veículo de maior abrangência no país - mas isso retorna significativamente sobre a questão ecológica.

$\mathrm{O}$ questionamento realizado pelo trabalho aqui resenhado dirigiu-se em especial para a forma de inclusão do tema da ecologia que foi produzida pela televisão, considerando em que medida responde às necessidades políticas que integram a posição ambientalista. Dado esse foco, a análise deixa de aproveitar elementos que ela mesma traz, no sentido de uma compreensão sobre os efeitos da mídia e do discurso ecológico assim difundidos pela sociedade.

No que diz respeito ao significado do programa na grade de programação da emissora como um todo, Amaral Neto e Globo Ecologia são muito diferentes. Esse "diferencial" é um elemento constitutivo da própria mídia: os programas são identificados pela sua correspondência a uma imagem de público enquanto consumidor. Nesse sentido, o primeiro figura como típico do jornalismo sensacionalista, e o segundo associa-se à imagem educativa própria às produções da Fundação Roberto Marinho.

$\mathrm{Na}$ análise do autor, essa diferença em relação ao significado dos programas na grade de programação da emissora não aparece como dado relevante. Quanto a Amaral Neto, tratase de um programa exibido em horário nobre, e, quanto a Globo Ecologia, um programa exibido aos sábados pela manhã.
Associar explicitamente tal consideração à análise conduziria a resultados expressivos, no que diz respeito ao sentido da natureza como objeto de reportagem na televisão brasileira. Nessa resenha, procurei, portanto, constribuir nessa direção.

Amaral Neto é um programa conservador em termos de mentalidade política, o que foi apontado na análise de Andrade. Nele, a natureza é abordada de forma sensacionalista, e os títulos dos programas analisados, como "Pororoca, o monstro das mil faces" e "Atol das Rocas, ilha do nada" (ambos realizados entre 1976 e 1978), são indicativos nesse sentido. De autoria do próprio Amaral Neto, os títulos apontam para a produção de um sentido hostil para o ambiente da natureza: lugar do monstruoso, do desolamento...

Evidencia-se o fato do programa Amaral Neto ser veiculado no momento em que a televisão cresce efetivamente pelo país, que, por sua vez, dirige-se ao desenvolvimento, à modernidade. A apresentação da natureza como esse outro lado ainda a ser explorado é parte do processo discursivo em que se constrói a identificação do Brasil como um país urbano, e portanto rumo ao "progresso". Trago aqui tais dados, com relação à identidade urbana do Brasil, e como ela vai se costruindo associada à imagem produzida na institucionalização da televisão como televisão nacional. ${ }^{1}$

1. Cf. SILVA, Telma Domingues da, Televisão brasileira - a Comunicação institucionalizada, tese de doutoramento desenvolvida no IEL - Instituto de Estudos da Linguagem/ Unicamp, 2002. 
$\mathrm{Na}$ análise do programa Amaral Neto, Thales de Andrade observa que o repórter dava poucas informações a respeito dos locais que eram objeto de suas reportagens. Essa observação associa-se à discussão que o autor faz do papel da tecnologia da imagem no interior desse programa: de que forma a câmera vai significar, enquanto instrumento que estabelece relações do público para com um determinado tema? Houve, portanto, uma consideração especificamente em relação à materialidade da linguagem da televisão.

Em tal contexto, a tecnologia da mídia mostra-se, segundo o autor, como uma força bélica, pela capacidade de levar até seu público as imagens de um país ainda por ser desbravado. A câmera é então a "arma" do repórter, que se identifica ao aventureiro-explorador, e a naturezaobjeto que se apresenta sob esse olhar é o ambiente agressivo, de acesso difícil, quase impossível, que pode até ser "monstruoso".

Os dados trazidos por essa pesquisa podem ser compreendidos do ponto de vista do processo históricodiscursivo que envolve a institucionalização da televisão brasileira. À década de 70, corresponde o crescimento dessa instituição, que vai se estabelecendo pelo território nacional. O programa Amaral Neto é bom exemplo para uma reflexão sobre o que essa imagem - que se diz ser "para todo o país" - podia representar naquele momento.

As produções televisivas na década de 70 não tinham ainda o caráter "profissional" que irá se constituir na década de 80. Mesmo assim, a tecnologia da imagem é tal que, junto aos outros elementos no qual se insere, isto é, associada ao crescimento das cidades e de seu modo de vida, a televisão é em grande parte responsável pela afirmação da modernidade do país, do seu desenvolvimento.

A partir da década de 70 , a força da imagem eletrônica começa a se mostrar em todo o seu poder, com o videoteipe, que permite a gravação e a edição das imagens, com a cor, com a rede, que permite transmissão simultânea para todo o território nacional, e com as gravações externas, que colocam o repórter presente "no local". Isto é, a imagem da televisão produz para a reportagem o sentido de que é "mais" do que uma narração, a reportagem é a própria imagem do repórter no vídeo, quando ele se mostra "lá", ao lado ou à frente do assunto que ele está "trazendo" ao público, não com as suas palavras, mas com "imagens reais"...

O sentido da imagem como algo "direto", que não precisa de "explicações", remete ao impacto da imagem como algo novo e moderno. Porém, diante do que hoje se apresenta como tecnologia da imagem, aquelas produções podem aparentar uma abordagem superficial e até um tanto rude.

\section{Amaral Neto e Globo Ecologia} remetem a dois contextos diferentes em termos de uma valorização da natureza: se no primeiro temos a natureza como um ambiente hostil a ser desbravado - o que é bem frisado na análise do autor -, no segundo temos uma natureza que pode ser amigável, e para isto deve ser compreendida - essa é uma interpretação que poderia ter sido feita, com base nos dados levantados. Na abordagem educativa/ científica (técnica) do Globo Ecologia, 
mostra-se necessária a compreensão daquilo que constitui o ambiente natural: saber, por exemplo, como vivem os animais, ter noção sobre a diversidade de plantas e de insetos em um ecossistema aparentemente pobre, do papel de um pequeno organismo em um ciclo amplo de vida, que envolve muitas outras espécies etc.

$\mathrm{O}$ autor aponta para o fato de que, de Amaral Neto ao Globo Ecologia, a forma como a natureza é apresentada ao público ganha especificidade. No lugar da "mata" ou dos "pássaros", mais gerais, o tratamento técnico e científico faz aparecerem termos como "biodiversidade" e "plano de manejo" por exemplo. Essa observação pode também ser interpretada: que efeitos tem essa linguagem técnica para o público enquanto cidadão?

A inclusão do tema do ambiente nas políticas públicas e na imprensa remete à possibilidade de uma conscientização do cidadão comum, que o obriga a manifestar um certo domínio sobre os processos que envolvem, não exatamente a natureza, mas a expansão do modo de vida urbano, entre a produção de bens e o consumo de recursos naturais por exemplo...

Embora haja essa diferenciação, de um programa a outro, com relação à especificidade da linguagem que refere o ambiente da natureza, o que se mantém, em uma e outra abordagem jornalística, é o fato de que o público da televisão, identificado como sujeito urbano, é sempre "estranho à natureza”: ou na natureza hostil ou na natureza amigável. Lembramos que, nesse último caso, a aproximação é feita através do conhecimento técnicocientífico, que muitas vezes desautoriza aqueles que vivem mais próximos à natureza - a não ser que o seu modo de vida seja exemplar, confirmando o sentido de proteção da natureza.

Como nos mostra Thales de Andrade, a gerência que Amaral Neto realiza do programa deixa nele a sua expressão, que aparenta uma marca pessoal, mas que manifesta, sobretudo, uma determinada atuação políticopartidária. $O$ autor vai analisar esse aspecto trazendo a conhecida reflexão de W. Benjamim, em que ele compreende a superação da figura do narrador com o advento da imprensa. Trata-se do ensaio "O narrador" (cf., por exemplo, volume da coleção Os Pensadores da Abril Cultural).

A inclusão da reflexão de Benjamim teve um efeito contraditório para com a análise do autor, reforçando a compreensão da imprensa como um "tratamento objetivo do fato", que Amaral Neto estaria deixando de lado ao tomar a palavra como narrador (e não como repórter, que é o que sustenta a designação do programa...). Ressalta no texto de Benjamim a crítica à imprensa, pela compreensão do narrador como aquele que permite uma abordagem integrada do acontecimento, histórica, que o jornalismo vem fragmentar com o fato-notícia enquanto "novidade".

A forma como Amaral Neto conduz as reportagens poderia, por exemplo, ser analisada do ponto de vista da locução. Sem entrar muito nas questões mais conceituais da enunciação, pode-se dizer que a locução do programa Amaral Neto produz-se através de uma sobreposição de dois lugares sociais: o do repórter e o do deputado da ARENA. O repórter Amaral Neto, portanto, não se identifica com a imprensa como um "olhar 
neutro" sobre o fato-jornalístico. E, dessa forma, a reportagem em seu programa assume um sentido específico, pois resulta da tarefa de falar das riquezas do Brasil como riquezas da Nação: trata-se de uma exaltação. Essa é uma maneira específica de fazer reportagem, que gostamos de pensar que não teria mais lugar em uma televisão "profissional", institucionalizada.

De Amaral Neto para o Globo Ecologia, os atores ou as autoridades que podem se mostrar falando com propriedade do meio ambiente teriam se ampliado. A natureza não é hoje remetida preferencialmente à questão dos limites territoriais, e tratada como de segurança pública, como era durante o regime militar.

Porém, o sentido de exaltação das riquezas naturais não só não desaparece da televisão brasileira, como continua prevalecendo. É ele o que mais encontramos nos chamados "horários nobres", quando a televisão se dirige ao grande público, isto é, a um público sem especificação etária ou de gênero. Mais recentemente, o Globo Repórter, embora não mostre o exagero quase caricato de Amaral Neto, também narra a natureza como uma aventura distante, selvagem. Esse, é claro, é um outro momento histórico, em que os recursos naturais serão ainda um tesouro a ser descoberto, explorado, mas agora pela ciência - e, através desta, as mesmas condições colonialistas e nacionalistas, que marcavam as relações internacionais nas décadas de 60 e 70, podem se recolocar. ${ }^{2}$

2. SILVA, Telma Domingues da, A Biodiversidade e a Floresta Tropical no discurso de meio ambiente e desenvolvimento - dissertação de mestrado desenvolvida no IEL/Unicamp, 1995.
Os dados que Thales de Andrade traz sobre as reportagens de Amaral Neto, que tem uma produtora própria, e sobre a Fundação Roberto Marinho, que produz o Globo Ecologia, são muito apropriados para uma reflexão sobre a forma de constituição do programa de televisão, em sua exibição para um público brasileiro. Ao mesmo tempo em que se constitui uma diferenciação para esses programas, como produtos voltados para um mercado específico, mostra-se também um efeito de indiferenciação, dado o sentido de entretenimento que atravessa a mídia como um todo.

A questão do entretenimento foi considerada por Andrade. Em Amaral Neto, o sensacionalismo evidencia o caráter de entretenimento para a abordagem do programa; em Globo Ecologia, outros elementos vêm se mostrar. O autor aponta para a utilização do videoclipe e para o fato de que a apresentação do programa não é feita por um jornalista, mas por um jovem ator. Esses são elementos extremamente significativos, do meu ponto de vista. A justificativa para essa forma de apresentação é certamente o de poder, com isso, aproximar a questão ecológica do jovem brasileiro. E assim estar realizando a "sua parte" na cidadania, como empresa responsável que é. Ou seja, a produção/exibição de um programa como Globo Ecologia, entre outros, tem efeito de marketing para a emissora Globo enquanto empresa.

A pesquisa de Thales de Andrade contribui efetivamente para uma compreensão em relação à forma como o meio ambiente apresenta-se na televisão. Embora tema obrigatório de reportagem, isto se dá de modo específico, tendo em vista a produção do espetáculo 
e/ou do espetacular, como elemento constitutivo da linguagem do meio.

No decorrer desse trabalho, a discussão em relação ao sentido de espetáculo, ou de entretenimento, produzido nos programas de televisão, volta-se preferencialmente para um questionamento sobre como isso pode ser encarado do ponto de vista de uma posição ambientalista. Ou seja, a entrada do tema na grande imprensa pode ter sido aplaudida ou criticada pelos diferentes grupos que compõe o movimento ecológico: Que significado isso pode ter? $\mathrm{O}$ que se ganha e o que se perde com isso? A discussão sobre o meio ambiente será por um lado absorvida pela linguagem da televisão, no sentido do espetáculo. Subsiste, por outro lado, a importância do domínio dessa linguagem pelas organizações ambientalistas, de modo a que estas possam ocupar o espaço da mídia com uma contribuição diversificada.

\section{"A Re-volta da Ecologia Política" Conflitos Ambientais no Brasil Henri Acselrad (org.) \\ Rio de Janeiro: Relume-Dumará, 2004, pp.294.}

\section{ANDRÉA ZHOURI*}

Os movimentos sociais surgidos no mundo a partir de 1960 foram acompanhados por debates intelectuais que buscavam novas bases para as Ciências Sociais. Notadamente, tentou-

* Professora do Departamento de Sociologia e Antropologia da Universidade Federal de Minas Gerais (UFMG) se superar dicotomias como objetividadesubjetividade, indivíduo-sociedade, e natureza-cultura. Os esforços para a superação da dicotomia natureza-cultura ligavam-se ao surgimento de uma crítica ambiental da sociedade industrial emanada de um movimento simultaneamente político e acadêmico denominado "ecologia política". Crítica em relação aos custos crescentes da reprodução do sistema produtivo, a ecologia política ia além da análise das contradições do modo de produção capitalista para denunciar uma alienação mais radical que a simples expropriação da mais-valia, qual seja, a alienação entre a sociedade industrial e a natureza.

O surgimento dessa crítica suscitou, contudo, reações por parte dos defensores da industrialização enquanto evolução inevitável. Os ecologistas passaram a ser desqualificados como românticos e ingênuos opositores do progresso. Entretanto, os problemas relativos à poluição e à escassez de recursos para a produção industrial não passaram desapercebidos pelos paladinos do desenvolvimentismo, sendo paulatinamente incorporados como "variáveis ambientais" legítimas no debate sobre a sociedade industrial. Nesse sentido, uma certa despolitização do debate ecológico foi ocorrendo na medida mesma em que as forças hegemônicas da sociedade reconheciam e institucionalizavam aqueles temas ambientais que não colocavam em cheque o modelo de sociedade vigente.

Foi assim que a década de 1990 consagrou o termo "desenvolvimento sustentável" como um campo de reconhecimento da chamada "crise ambiental" em escala planetária - crise entendida 